\title{
Microvascularisation of the scrotal integument of Holstein-Friesian bulls
}

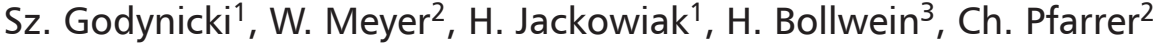 \\ ${ }^{1} 1^{\text {st }}$ Department of Histology and Embryology, Poznan University of Life Sciences, Poznan, Poland \\ 2Institute for Anatomy, University of Veterinary Medicine Hannover Foundation, Hannover, Germany \\ ${ }^{3}$ Clinic for Large Animal Reproduction, Vetsuisse Faculty, University of Zurich, Zurich, Switzerland
}

\begin{abstract}
Based on standard histological methods and specific injection technique, the study demonstrates for the first time the blood vessel system of the scrotal integument. The latter is relatively thin and shows a thick underlying fascia, the tunica dartos. The vessel networks found in both structures are somewhat different from each other, i.e., the former displays the typical integumental vessel scheme, which, because of its thinness, shows a higher vessel density. The tunica dartos displayed a blood vessel system with specific characteristics, i.e. horizontal networks are present, which are on the one hand directly connected to the rete dermidis and on the other hand, with the ascending (arteries) or descending (venes) vessels of the dartos, so that a rather uniform distribution and nutrition of the latter, including its muscle layers, is assured.

The findings support the idea that the functions of the scrotal integument and the dartos are based on a dependable energy supply, but with regard to vessel type, particularly arteries, may also be involved in the regulation of blood flow. Thus, the scrotal integument as well as the dartos can be used for thermoregulation. (Folia Morphol 2013; 72, 2: 132-136)
\end{abstract}

Key words: scrotal integument, tunica dartos, blood vessel networks, thermoregulation, Holstein-Friesian bull

\section{INTRODUCTION}

Although the ideal temperature for sperm growth varies between mammalian groups, it usually appears in warm-blooded species to be somewhat cooler than internal body temperature, leaving the testicles vulnerable. Thus, many findings emphasize the importance of thermoregulation to sperm production and seminal quality [3, 4, 10-13, 22, 23]. The evolutionary advantage of such a system must be connected with the scrotum to keep the testes at a temperature slightly lower than that of the rest of the body because higher temperatures may be damaging to sperm count. In contrast to the arterial and venous anastomoses between the 3 main vessels of the scrotal organs and spermatic cord, which are the basis for a complex vasculogenic stabilising mechanism to protect the testicle, epididymis, and vas deferens [1, 2], the specific role of the scrotal integument and, particularly, of its blood vessel system has still to be clarified. In this context the present study demonstrates for the first time the typical structure of blood vessel organisation in the dermis and the related tunica dartos using reliable histological and injection techniques.

\section{MATERIALS AND METHODS}

For our study, skin samples of the scrotum of 3 adult Holstein-Friesian bulls from the Clinic for Buiatrics of the University of Veterinary Medicine Hannover Foundation (Germany) were obtained di- 


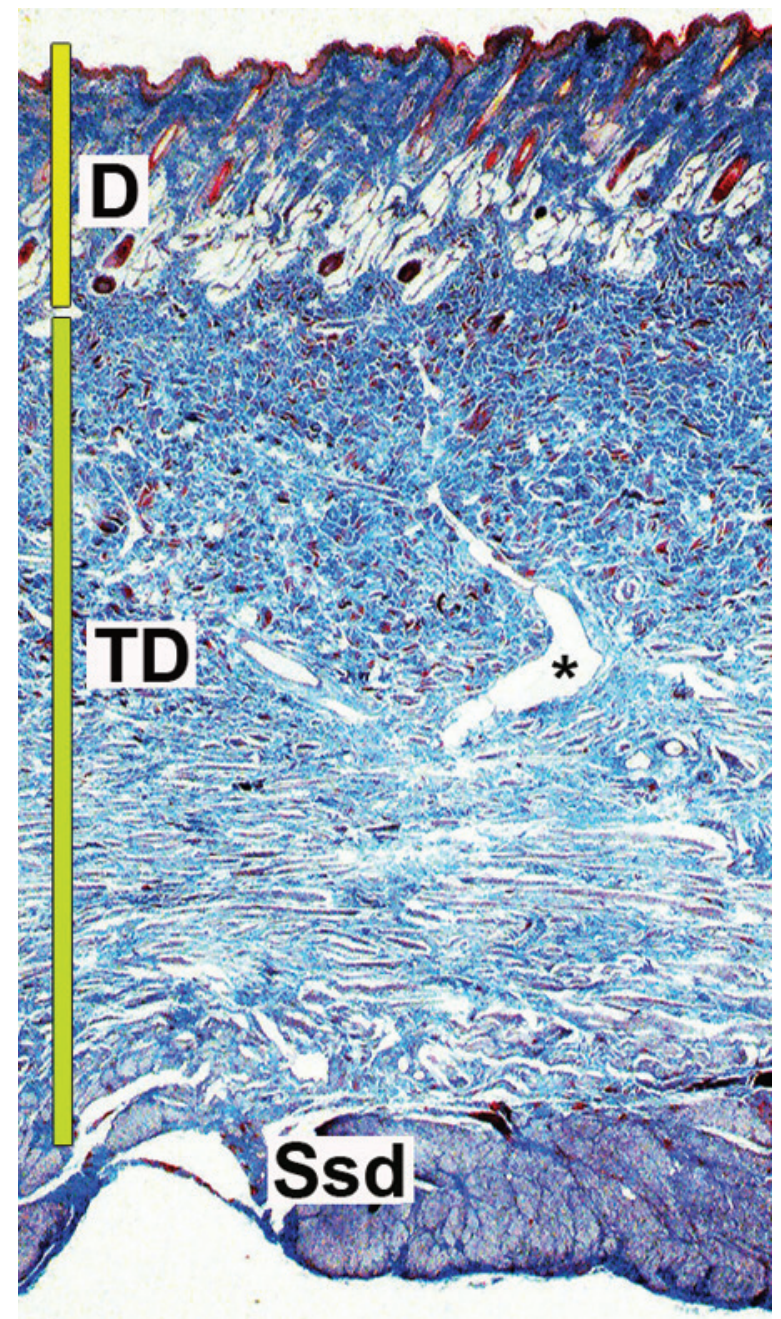

Figure 1. General structure of the scrotal integument with the massive tunica dartos and the lowest dartos layer (stratum subdartoicum), thickness of the dermis about $1.6 \mathrm{~mm}$, thickness of the tunica dartos about $\mathrm{mm}$; very apparent are the large secretory parts of the apocrine glands forming a layer in the deep part of the dermis. Additionally, a lymphatic vessel is shown (asterisk); Masson staining; D - dermis, TD — tunica dartos, Ssd — stratum subdartoicum.

rectly after euthanisation in the slaughterhouse, and a) routinely processed for standard histological purposes, i.e. fixation in Bouin's solution, paraffin embedding, $8 \mu \mathrm{m}$ sections, $\mathrm{HE}$ and Masson staining, and b) injected with a 1:4 mixture of India ink and blood serum through the arteria pudenda externa, fixated in $4 \%$ formalin, dehydrated, cleaned in benzoyl, and stored in a 1:1 mixture of methyl benzoate/benzyl benzoate. Blocks of the injected skin were then cut both, vertically and horizontally to the skin surface, into $70 \mu \mathrm{m}$ serial sections (for the technique see $[6,8])$. The findings were documented with a stereomicroscope Discovery $\vee 20$ (Zeiss) and photomicroscope Axioscope 2 plus (Zeiss).
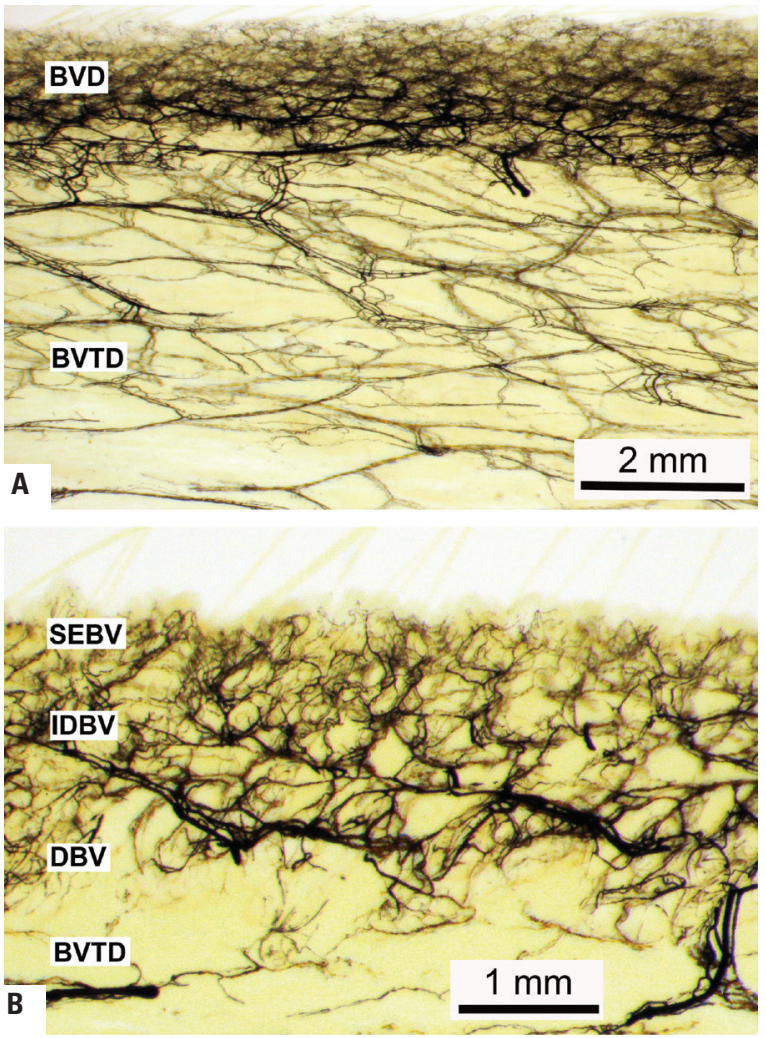

Figure 2A, B. Blood vessel systems of the dermis and the upper tunica dartos; the dense network of the thin dermis is remarkable; India ink injection technique; BVD - blood vessel network of the dermis; BVTD — blood vessel network of the tunica dartos; SEBV — subepidermal blood vessel system; IDBV — intradermal blood vessel system; DBV — deep dermal blood vessel system.

\section{RESULTS}

The scrotum is covered by a thin integument and a thick underlying fascia, the tunica dartos (Fig. 1). Regarding blood vessel supply (for blood vessel nomenclature see [17]), in the former a stratum superficiale dermidis with a dense sub-epidermal system of ansa capillaris was obvious (Fig. 2). The very distinct horizontal network of the rete arteriosum subepidermalis/ plexus venosus subepidermalis below this region revealed relatively large glomerular structures (Figs. 2B, 3B). Such a system is normally rather inconspicuous in the trunk regions of mammals. More deeply, the zone of the secretory parts of the apocrine glands marks the structural change between the upper part of the dermis with hair follicles and the strong collagen fibre bundles of the thick medium layer of the dermis (Figs. 3A). Moreover, a very dense blood vessel supply of the large and convoluted secretory units of the latter gland type (Fig. 4) is emphasized, the strong blood vessels of which connect every apocrine gland with the rete/plexus dermidis (Fig. 4B). In general, 


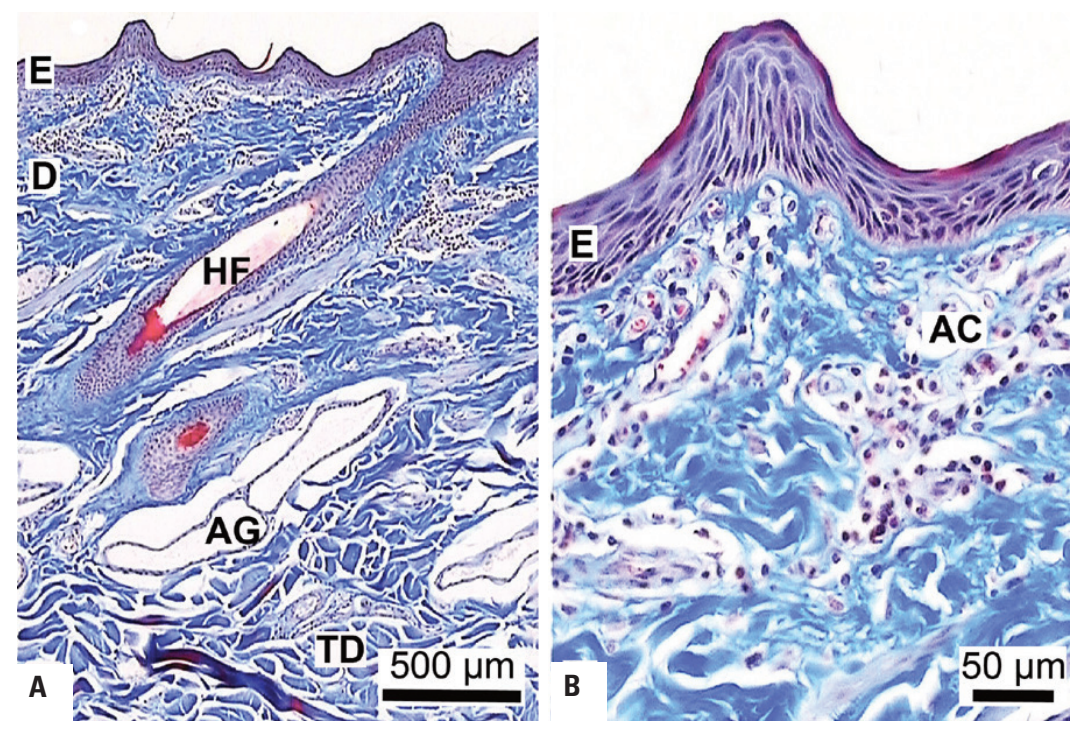

Figure 3. Structure of the upper (A) and the subepidermal dermis (B); the network of the rete arteriosum subepidermalis/plexus venosus subepidermalis reveals relatively large glomerular structures (B); Masson staining; $\mathrm{E}$ - epidermis; D — dermis; AC — arterial conglomeration; AG — secretory part of apocrine glands; HF — hair follicle; TD — upper part of the tunica dartos.

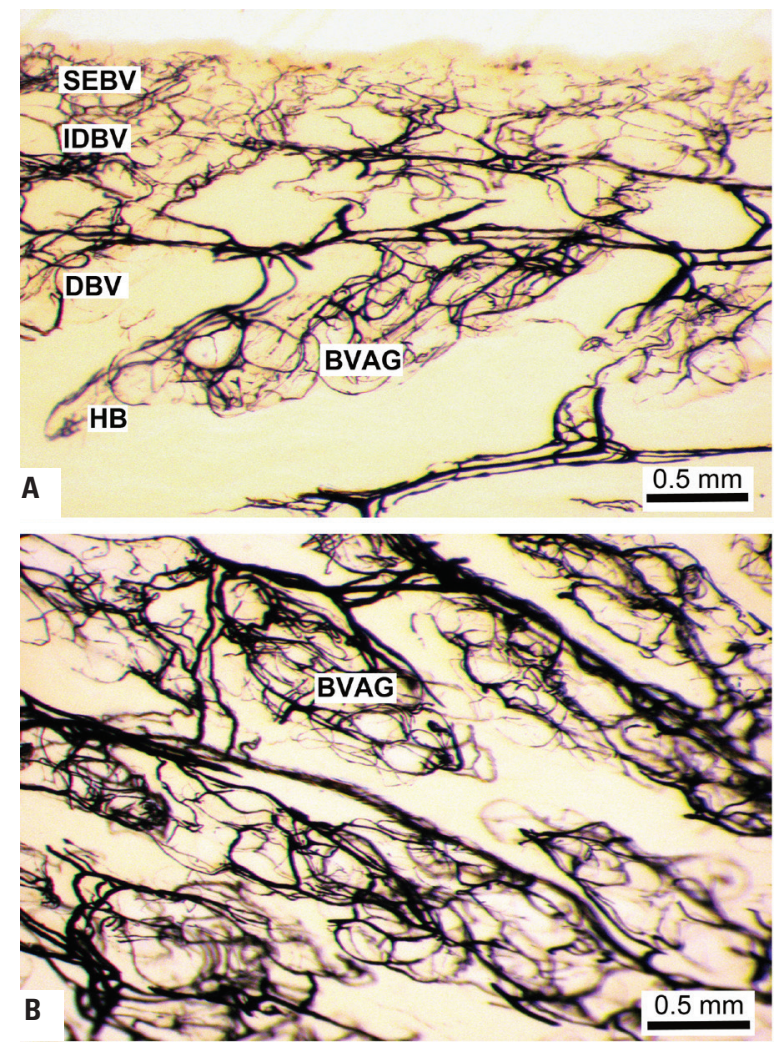

Figure 4. Demonstration of the very effective blood vessel supply of the secretory parts of the apocrine glands (A. Sagittal section; B. Horizontal section); India ink injection technique; BVAG — blood vessel supply system for the secretory parts of the apocrine; SEBV subepidermal blood vessels system; IDBV — intradermal blood vessel system; DBV — deep dermal blood system; HB — hair bulbus.

this construction is unique compared with the blood vessel network of the lower dartos (see below). In particular, the remarkable plexus system showing vessels with a large diameter creates voluminous collecting reservoirs for functional blood in the total dermis (see e.g. Fig. 2B).

The following compact tunica dartos, which can be regarded as a specific derivative of the hypodermis but devoid of adipose tissue, additionally contains smooth muscle and fibroelastic tissue layers, despite being collagen-dominated. According to this construction, the blood vessel system of the tunica dartos is built up of horizontal networks lying one upon the other, as consisting of polygonal meshes often formed by paired vessels (arterioles/venules) (Figs. 2A, 5A). The most deeply found blood vessel layer is still part of the tunica dartos (Fig. 5B) because it is present in the lowest dartos layer, also known as the stratum subdartoicum [9], which mainly consists of smooth muscle groups that are organised by supporting tissue (Fig. 1).

\section{DISCUSSION}

The findings of our study clearly demonstrate that the vessel networks of the scrotal skin and the tunica dartos are somewhat different from each other, i.e., the former displays the typical integumental vessel scheme [17] but because of its thinness a higher vessel density. The tunica dartos, however, displayed a blood vessel system that showed specific characteristics not known until now. This means that horizontal networks are present, which are on the one hand directly connected to the rete dermidis, 


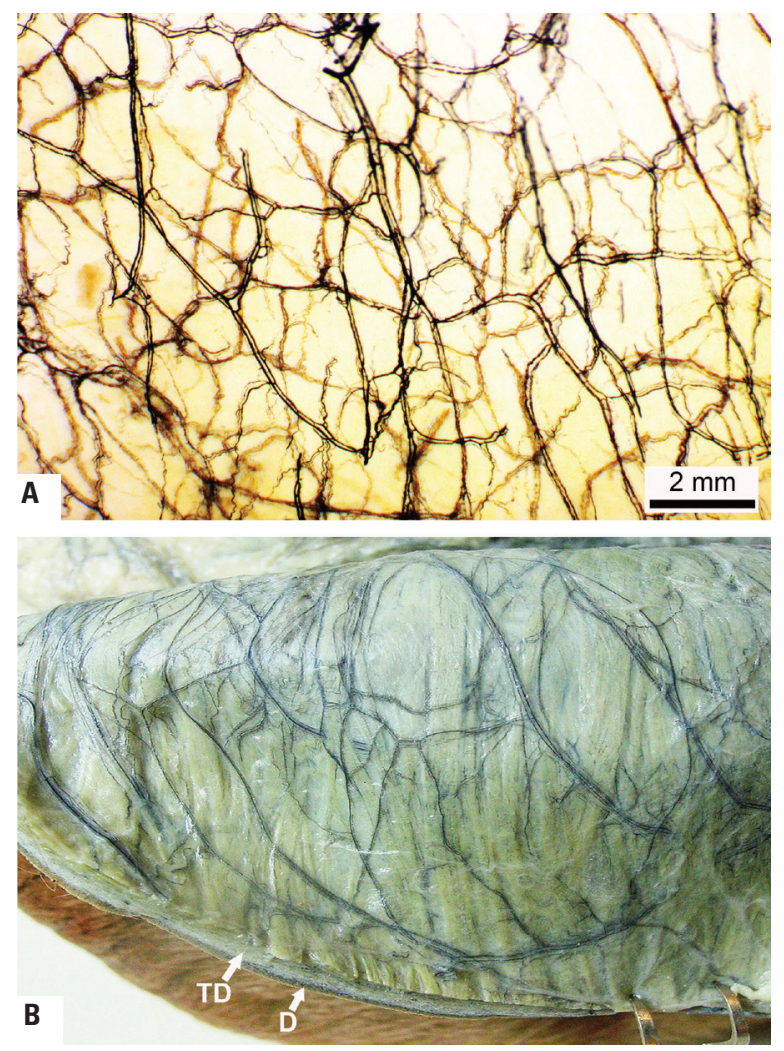

Figure 5. Horizontal blood vessel layer of the upper tunica dartos (A) and view of the blood vessels of the stratum subdartoicum (B); India ink injection technique; D — dermis; TD — tunica dartos.

and on the other hand with the ascending (arteries) or descending (venes) vessels of the dartos, so that a rather uniform distribution and nutrition of the latter, including its muscle layers, is assured.

Such a view not only supports the idea that the functions of the scrotal integument and the dartos are based on a dependable energy supply, but with regard to vessel type, particularly arteries, may also be involved in the regulation of blood flow $[12,13]$. Thus, the integument as well as the dartos can be used for thermoregulation.

For example, the arrangement of the scrotal blood vessels is related to temperature changes from the scrotal surface to the intratesticular regions, creating temperature gradients. In bulls, such gradients from top to bottom are most pronounced for the scrotal surface temperature, smaller for the dartos layers and slightly negative (relative to the surface) for intratesticular temperatures [12-14]. Nevertheless, differences in vascular arrangement, characteristics of the artery (e.g. wall thickness), or thickness of the tunica albuginea may affect the testicular arterial blood flow and subtunic temperatures. This view is confirmed by the fact that increased sperm quality and production not only seems to be associated with increased testicular volume or testicular temperatures, but additionally with the dartos temperature gradient and the scrotal surface [3]. Moreover, for the number of spermatozoa per ejaculate and for the percentage of motile spermatozoa, plasma testosterone concentrations together with differences between top and bottom scrotal surface temperatures were significant independent variables [7]. These findings corroborate the view that the fine and dense blood vessel network of the scrotal dermis is generally involved in thermoregulation by heat emission $[5,7,13]$. In this context it has to be emphasized that the secretions of the apocrine tubular glands are not involved in thermoregulative activities but in antimicrobial defence to protect the skin and, here particularly the sparsely haired scrotal surface, against microbial invasion $[15,18,20,21,24,25]$. In this context, the excellent vascular supply of the scrotal apocrine glands, as shown in our study, supports strong and continuous secretion production. The latter functional aspect is primarily related to domestication influences, i.e. whereas under natural conditions glandular activity shows seasonal control [19], many intensely bred domesticated animals exhibit continuously increased glandular secretion rates and distinct changes in the secretion composition with subsequent changes in the spectrum and activities of the microbial flora on the epidermal surface (for review see [16]).

\section{REFERENCES}

1. Artyukhin AA (2007a) Anatomy and microanatomy of the venous system of scrotal organs and spermatic cord. Bull Exp Biol Med, 143: 99-104.

2. Artyukhin AA (2007b) Vascular buffer system of the scrotal organs. Bull Exp Biol Med, 143: 642-647.

3. Brito LFC, Silva AEDF, Barbosa RT, Kastelic JP (2004) Testicular thermoregulation in Bos indicus, crossbred and Bos taurus bulls: relationship with scrotal, testicular vascular cone and testicular morphology, and effects on semen quality and sperm production. Theriogenology, 61: 511-528.

4. Cook RB, Coulter GH, Kastelic JP (1994) The testicular vascular cone, scrotal thermoregulation, and their relationship to sperm production and seminal quality in beef bulls. Theriogenology, 41: 653-671.

5. Coulter GH, Senger PL, Bailey DRC (1988) Relationship of scrotal surface temperature measured by infrared thermography to subcutaneous and deep testicular temperature in the ram. J Reprod Fertil, 84: 417-423.

6. Fath El-Bab MR, Schwarz R, Godynicki Sz (1983) The morphogenesis of the vasculature in the skin. J Anat, 136: 561-572. 
7. Gábor G, Sasser RG, Kastelic JP, Coulter GH, Falkay G, Mézes M, Bozó S, Völgyi-Csík J, Bárány I, Szász F Jr (1998) Morphologic, endocrine and thermographic measurements of testicles in comparison with semen characteristics in mature Holstein-Friesian breeding bulls. Anim Reprod Sci, 51: 215-224.

8. Godynicki Sz, Fath El-Bab MR, Schwarz R (1985) Die Anordnung der Blutgefäße in der Haut beim Schwein zum Zeitpunkt der Geburt. Anat Histol Embryol, 14: 304-315.

9. Hartig F (1965) Das Stratum perivaginale im Bereich des Scrotum und der Inguinalgegend und seine chirurgische Bedeutung. Zbl Vet Med (Ser A), 12: 881-887.

10. Hjollund NHI, Bonde JPE, Jensen TK, Olsen J (2000) Diurnal scrotal skin temperature and semen quality. Int J Androl, 23: 309-318.

11. Hjollund NHI, Storgaard L, Ernst E, Bonde JPE, Olsen J (2002) Impact of diurnal scrotal temperature on semen quality. Reprod Toxicol, 16: 215-221.

12. Kastelic JP, Cook RB, Coulter GH (1997a) Contribution of the scrotum, testes, and testicular artery to scrotal/ /testicular thermoregulation in bulls at two ambient temperatures. Anim Reprod Sci, 45: 255-261.

13. Kastelic JP, Cook RB, Coulter GH (1997b) Scrotal/testicular thermoregulation and the effects of increased testicular temperature in the bull. Vet Clin North Amer, Food Anim Pract, 13: 271-282.

14. Kastelic JP, Coulter GH, Cook RB (1995) Scrotal surface, subcutaneous, intratesticual, and intraepididymal temperatures in bulls. Theriogenology, 44: 147-152.

15. Meyer W (2007) Demonstration of lysozyme and antimicrobial peptides in the temporal gland of the African elephant (Loxodonta africana). Mammal Biol, 72: 251-255.

16. Meyer W (2009) Hair follicles in domesticated mammals, with comparison to laboratory animals and humans. In:
Mecklenburg L, Linek M, Tobin DJS eds. Hair loss disorders in domestic animals. Blackwell Publishers, Ames, lowa, USA, pp. 43-62.

17. Meyer W, Godynicki Sz, Tsukise A (2008) Lectin histochemistry of the endothelium of blood vessels in the mammalian integument, with remarks on the endothelial glycocalyx and blood vessel system nomenclature. Ann Anat, 190: 264-276.

18. Meyer W, Neurand K, Tanyolaç A (2001) General antimicrobial properties of the integument in fleece producing sheep and goats. Small Rum Res, 41: 181-190.

19. Meyer W, Seegers U, Bock M (2008b) Annual secretional activity of the skin glands in the Southern pudu (Pudu puda Molina 1782, Cervidae). Mammal Biol, 73: 392-395.

20. Meyer W, Seegers U, Herrmann J, Schnapper A (2003) Further aspects of the general antimicrobial properties of pinniped skin secretions. Dis Aquatic Org, 53: 177-179.

21. Nara T, Yasui T, Fujimori O, Meyer W, Tsukise A (2012) Histochemical analyses of antimicrobial substances in canine perianal skin with special reference to glandular structures. Anat Histol Embryol, 41: doi: 10.1111/j.1439-0264.2012.01171.x (in press).

22. Neya T, Pierau FK (1976) Vasomotor response to thermal stimulation of the scrotal skin in rats. Pflügers Arch, 363: 15-18.

23. Purohit RC, Hudson RS, Riddell MG, Carson RL, Wolfe DF, Walker DF (1985) Thermography of the bovine scrotum. Am J Vet Res, 46: 2388-2392.

24. Stoeckelhuber M, Stoeckelhuber BM, Welsch U (2004) Apocrine glands in the eyelid of primates contribute to the ocular host defense. Cells Tiss Org, 176: 187-194.

25. Yasui T, Fukui K, Nara T, Habata I, Meyer W, Tsukise A (2007) Immunocytochemical localization of lysozyme and beta-defensin in the apocrine glands of the equine scrotum. Arch Dermatol Res, 299: 393-339. 